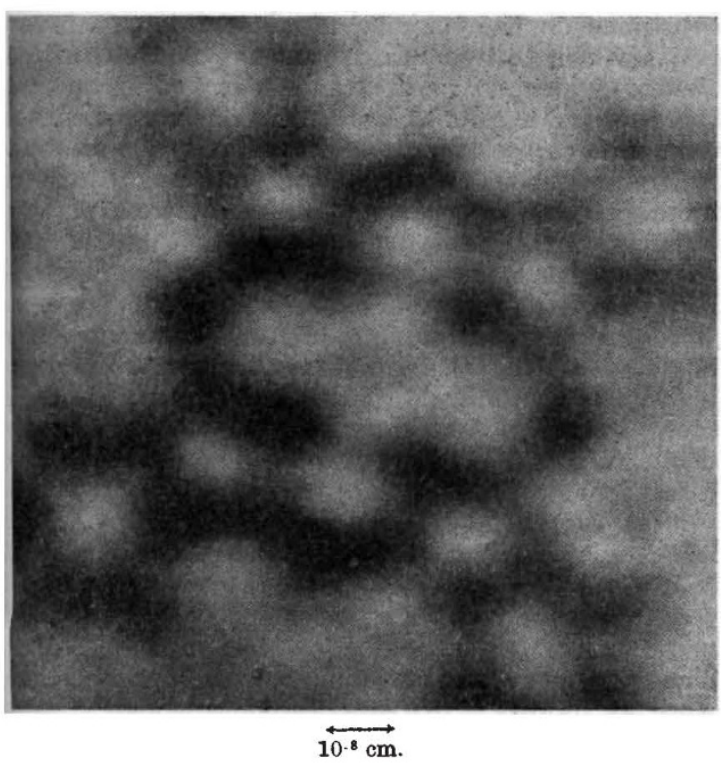

Fig. 2. Photugraph of a phthalocyanine Molectle, FRom X-RAY DATA BY ROBERTSON ${ }^{4}$.

cell. If the distribution of light transmission through each mask is

$$
1+\cos 2 \pi(h x+k y),
$$

the total light intensity reaching the photographic emulsion (on which the picture is being made) is the desired summation plus a uniform, unwanted background. The effect of this uniform background illumination can be nearly eliminated by using a photographic material-such as Velox F5, Kodalith paper or Kodalith film-with a suitable characteristic curve. Although not necessary for crystal structure analysis, the remaining background can be entirely removed by treatment with a reducer solution or by reprinting, using appropriate film and paper.

With the aid of the Physics Department of these Laboratories, an improved set of masks has recently been made, on a roll of $35 \mathrm{~mm}$. film. Examples of syntheses obtained with these new masks are shown in the accompanying figures. In Fig. I the back. ground has been partly removed by reprinting.

The departure from a perfect hexagonal structure in Fig. 1 is in part due to inclination of the molecule relative to the plane of the projection, and in part to the representation of the actual unit of the projection-a parallelogram with unequal sides and angles-by a square. In Fig. 2 these two factors practically cancel each other, the photograph showing the appearance of the phthalocyanine molecule with the line of vision normal to the plane of the molecule. If wanted, projections having the shape of the true unit can be produced by any of several procedures, now in process of being tested here.

We hope soon to be able to furnish copies of these masks, at a nominal cost, to others doing crystal structure work.

Kodak Research Laboratories,

MaUrice L. Huggins.

Rochester, N.Y.

Oct. 9.

${ }^{2}$ Bragg, W. L., Z. Krist., A, 70, 475 (1929) ; “The Crystalline State" (New York, Macmillan, 1934), p. 229.

'Huggins, M. L., J. Amer. Chem. Soc., 68, 66 (1941).

Brockway, L. O., and Robertson, J. Monteath, J. Chem. Soc., 1324 (1939).

‘Robertion, J. M., J. Chem. Soc., 1195 (1936).

\section{Grignard Compounds as Condensing Agents}

IT is already known that Grignard compounds may act as reducing agents ${ }^{1,2}$, or cause enolization of ketones $^{3,4}$, or bring about the condensation of esters of some fatty acids to $\beta$-keto-esters. The present communication records some observations on the condensation of ketones during the Grignard reaction.

It was observed during the preparation of some tertiary alcohols by reaction of alkylmagnesium halides with ketones that the product contained greater or smaller amounts of condensation product. Thus pinacolin (I) and tert.-butyl magnesium chloride gave as principal products, pinacolyl alcohol and a mixture of the hydroxy ketone (III) and the unsaturated ketone (II). None of the required alcohol could be isolated. Ethyl magnesium bromide also gave notable amounts of these condensation products, as did also phenyl magnesium bromide.

$$
\begin{gathered}
\left(\mathrm{CH}_{3}\right)_{3} \mathrm{C} \cdot \mathrm{CO} \cdot \mathrm{CH}_{3} \\
(\mathrm{I}) \\
\left(\mathrm{CH}_{3}\right)_{3} \mathrm{C} \cdot \mathrm{CO} \cdot \mathrm{CH}: \mathrm{C}\left(\mathrm{CH}_{3}\right) \cdot \mathrm{C}\left(\mathrm{CH}_{3}\right)_{3} \\
(\mathrm{III}) \\
\left(\mathrm{CH}_{3}\right)_{3} \mathrm{C} \cdot \mathrm{CO} \cdot \mathrm{CH}_{2} \cdot \mathrm{C}(\mathrm{OH})\left(\mathrm{CH}_{3}\right) \cdot \mathrm{C}\left(\mathrm{CH}_{3}\right)_{3} \\
(\mathrm{III})
\end{gathered}
$$

A survey of the literature has shown that the formation of condensation products from ketones during Grignard reactions has been frequently recorded without any further characterization or identification $^{1}$. Only two recorded examples of the identification of such products have so far come to our notice ${ }^{2,5}$. It would now appear that the self-condensation of ketones during the Grignard reaction is more general than is commonly supposed, and that by selecting suitable reactants it may become the main reaction.

The experimental data at present available leads to the conclusion that alkyl magnesium halides with highly branched chains not only bring about reduction of the ketone but also promote condensation. The structure of the ketone is also an important factor; those with an available hydrogen adjacent to the carbonyl and a slow rate of reaction towards Grignard reagents condense more readily. If théy react with Grignard reagents which do not cause reduction, such as the aryl magnesium halides, the formation of the condensation is still more favoured. W. J. Hiскіn воттом. E. SCHIÜCHTERER.

Chemistry Department, University, Birmingham, I5.

${ }^{1}$ Conant and Blatt, J. Amer. Chem. Soc., 51, 1227 (1929).

${ }^{2}$ Whitmore et al., J. Amer. Chem. Soc., 63, 648 (1941).

"Grignard and Savard, Bull. Soc. chim., 35, 1081 (1924).

4 Kohler, Stone and Fuson, J. Amer. Chem. Soc., 49, 3181 (1927).

${ }^{5}$ Tolstopyatov, J. Russ. Phys. Chem. Soc., 62, 1813 (1930).

\section{Rates of Oxidation of Different Substrates in the Frog's Liver}

IN the course of preliminary studies in an investigation regarding the mechanism of the regulation by hormones of enzymic processes, we have carried out determinations of the respiratory quotient $(R Q)$ of the liver tissue with homogeneous material from the frog (Rana temporaria) in the summer state. For each specimen a determination of respiratory quotient was performed on slices by a modification ${ }^{1}$ of the method of Meyerhof and Schmitt. The values obtained varied between $0 \cdot 70$ and $1 \cdot 00$. When the values of the oxygen consumption per mgm. fresh weight were 